\title{
Use of a Mobile Application for Self-Monitoring Dietary Intake: Feasibility Test and an Intervention Study
}

\author{
Ji-Eun Lee ${ }^{1}$, Sihan Song ${ }^{2}$, Jeong Sun Ahn ${ }^{2}$, Yoonhee $\mathrm{Kim}^{3}$ and Jung Eun Lee ${ }^{2, *}$ \\ 1 Department of Food and Nutrition, Sookmyung Women's University, Seoul 04310, Korea; \\ jsilver1109@gmail.com \\ 2 Department of Food and Nutrition, College of Human Ecology, Seoul National University, \\ Seoul 08826, Korea; songsihan@snu.ac.kr (S.S.); jungsunan@snu.ac.kr (J.S.A.) \\ 3 Department of Computer Science, Sookmyung Women's University, Seoul 04310, Korea; \\ yulan@sookmyung.ac.kr \\ * Correspondence: jungelee@snu.ac.kr; Tel.: +82-2-880-6834
}

Received: 5 May 2017; Accepted: 7 July 2017; Published: 13 July 2017

\begin{abstract}
Given the increasing social and economic burden of chronic disease and the need for efficient approaches to prevent and treat chronic disease, emphasis on the use of information and communication technology (ICT)-based health care has emerged. We aimed to test the feasibility of a mobile application, Diet-A, and examine whether Diet-A could be used to monitor dietary intake among adolescents. In a three-month pre-post intervention study, 9 male and 24 female high school students aged 16-18 years consented and participated in this study. Participants were instructed to record all foods and beverages consumed using voice or text mode input. Nutrient intake was measured using 24-h recalls pre- and post-intervention. We compared nutrient intake data assessed by Diet-A application with those assessed by 24-h recalls. Participants tended to underreport intakes of nutrients compared to those assessed by two 24-h recalls. There were significant decreases in sodium $(p=0.04)$ and calcium $(p=0.03)$ intake between pre- and post-intervention. Of participants who completed questionnaires of feasibility $(n=24), 61.9 \%$ reported that they were satisfied using the application to monitor their food intake, and $47.7 \%$ liked getting personal information about their dietary intake from the application. However, more than $70 \%$ of participants answered that it was burdensome to use the application or that they had trouble remembering to record their food intake. The mobile application Diet-A offers the opportunity to monitor dietary intake through real-time feedback. However, use of Diet-A may not provide accurate information on the food intake of adolescents, partly because of the recording burden.
\end{abstract}

Keywords: mobile application; mobile health care; dietary assessment; feasibility; pre-post intervention

\section{Introduction}

The World Health Organization (WHO) reported that deaths caused by noncommunicable chronic diseases (NCD) are expected to increase from 36 million in 2010 to 44 million in 2020 [1]. The leading contributing factors to the global burden of disease in 2010 were high blood pressure, smoking, household air pollution, low fruit intake, and alcohol use [2], suggesting the importance of lifestyle in maintaining health. Given the increasing social and economic burden of chronic disease and the need for efficient approaches to prevent and treat chronic disease, emphasis on the implementation of information and communication technology (ICT)-based health care has emerged.

Advancements in technology have been expected to help health professionals and health care consumers teach and adopt healthy behaviors and prevent chronic disease in a cost-effective way. 
Diet is a major risk factor or prevention-related factor of noncommunicable chronic diseases including cancer, cardiovascular disease and diabetes. To prevent and control a noncommunicable chronic disease, the WHO established a strategy for healthy eating and physical activity and prepared a series of action plans [3], suggesting the importance of diet in maintaining a healthy life.

Assessment of dietary intake and intervention in dietary behaviors are key components in health care and public health. Accurate methods and tools to assess food and nutrient intake are essential in monitoring nutritional status. Twenty-four-hour dietary recall, dietary records, and food frequency questionnaires (FFQs) are commonly used to measure dietary intake [4]. Twenty-four-hour dietary recall can be administered by a trained interviewer, who asks the respondent for details of foods and beverages consumed within 24-h and records the information. Therefore, literacy of the respondent is not required, and the method can be used in a wide range of populations. However, this method depends on the respondent's memory and requires trained interviewers. For dietary records, the respondent records all foods and beverages consumed over one or more days. Although dietary records are often regarded as a gold standard, participants need to be highly motivated and have the ability to record the details of their own diet. A FFQ asks respondents to report their usual frequency of consumption of a list of provided foods for designated time periods. This method is useful for examining usual dietary intake in a large population, but a FFQ cannot contain all foods and beverages that an individual consumed. Given such limitation of each method, the accuracy of dietary measurement for free-living individuals remains challenging in nutritional epidemiology research.

Health-related behaviors, such as healthy eating and regular exercise, could lead to improvement in population health only if they are sustained. Mobile technologies can help people record their food intake and monitor their diet in real time. The ENGAGED randomized controlled trial examined the efficacy of a smartphone-supported weight loss program among adults whose BMI was between 30 and $40 \mathrm{~kg} / \mathrm{m}^{2}$ and found that self-guided intervention with use of a mobile phone could be a potential alternative to the face-to-face treatment [5]. In the ENGAGED trial, participants monitored their dietary intake using application of smartphone. Another weight loss program that implemented a mobile phone application "My Meal Mate" reported higher frequency of use and greater weight loss compared to a diary group or website group [6]. The convergence of information and communication technology (ICT) and nutrition may advance dietary assessment and help individuals obtain accurate and personalized data, leading to an improvement of their health through daily feedback.

According to research released in 2015, Korea (83\%) has been ranked fourth among 56 countries in smartphone penetration, outranked only by the United Arab Emirates(UAE) (90.8\%), Singapore (87.7\%), and Saudi Arabia (86.1\%) [7]. The International Telecommunication Union (ITU) reported that Korea ranked the first in the ITU's ICT Development Index (IDI), a composite measurement reflecting level of ICT access, use and skill [8]. Korea has great potential to test and evaluate mobile health care technology, given its high rate of smartphone use and good quality of ICT infrastructure.

Therefore, we developed a self-monitoring mobile dietary application, Diet-A, and tested its feasibility in a pre-post intervention study. We also aimed to examine whether the mobile application could be a useful tool for adolescents to monitor their dietary intake.

\section{Materials and Methods}

\subsection{Development of the Mobile Application}

We developed a dietary self-monitoring mobile application called 'Diet-A'; its development process has been published elsewhere $[9,10]$. The menu of the application was composed of three parts: records of dietary intake, real-time feedback, and provision of information on disease prevention in accordance with the participant's input (Figure 1). The structure of the Diet-A system allows input of dietary data, calculation of nutrients, comparison with dietary reference intake, production of descriptive statistics of nutrient intakes, and display of personalized advice, and a food recommendation list [9]. After users logged into Diet-A, they entered their sex, age, height and weight, 
and then their estimated energy requirements were calculated. To record their food, dish and beverage intake, users could speak or type in the name of the food, dish or beverage. When users spoke food, dish or beverage names, the application showed its name and the amount of one serving size on the screen. Users could check whether their voice was well recognized accordingly. If not, users could speak again or type in the name of the food, dish or beverage. Users then recorded the proportion of pre-specified portion size (e.g., 1 serving size of bowl). Daily energy and nutrient intakes were calculated by summing the nutrient content for quantities of foods and beverages consumed, which were calculated by multiplying grams of one pre-specified portion size by the proportion of portion size that they recorded. We used the database of National Rural Living Science Institute [11] for grams of one serving size commonly consumed in Korea. Users were instructed to take a photograph to remind them of foods, dishes, and beverages that they consumed on that day, so that they could record the meal later when they had time for data input. Also, Diet-A had a pop-up function that reminded users to record their meals if they did not record their breakfast, lunch or dinner until 11:00 a.m., 3:00 p.m. or 8:00 p.m., respectively. Diet-A provided real-time feedback on intakes of total energy, carbohydrates, protein, fat, saturated fat, sodium, calcium and iron based on the Dietary Reference Intakes for Koreans 2010 [12]. For energy intake, we compared individuals' energy intake with Estimated Energy Requirements of Dietary Reference Intakes for Koreans 2010 [12]; estimated energy requirement $=\alpha+\beta \times$ age (years) $+\mathrm{PA}[\gamma \times$ weight $(\mathrm{kg})+\delta \times$ height $(\mathrm{m})], \alpha$ : age-and-sex-specific constant, $\beta$ : age-and-sex-specific coefficient for age, $\gamma$ : age-and-sex-specific coefficient for weight, $\delta$ : age-and-sex-specific coefficient for height, and PA: coefficient for physical activity. Percent energy intake each from carbohydrate, fat and saturated fat was compared to the Acceptable Macronutrient Distribution Range. Intakes of sodium, calcium and iron were compared to intake goal or recommended intakes (RI) of Dietary Reference Intakes for Koreans 2010. On the feedback screen, intakes of total energy, carbohydrates, protein and fat and contribution of each macronutrient to energy were displayed. To build our database of foods and dishes, we used the database of Korea's Ministry of Food and Drug Safety [13], the food composition table of the National Rural Living Science Institute [8], KNHANES 24-h recall data and nutrient content provided by food product companies.

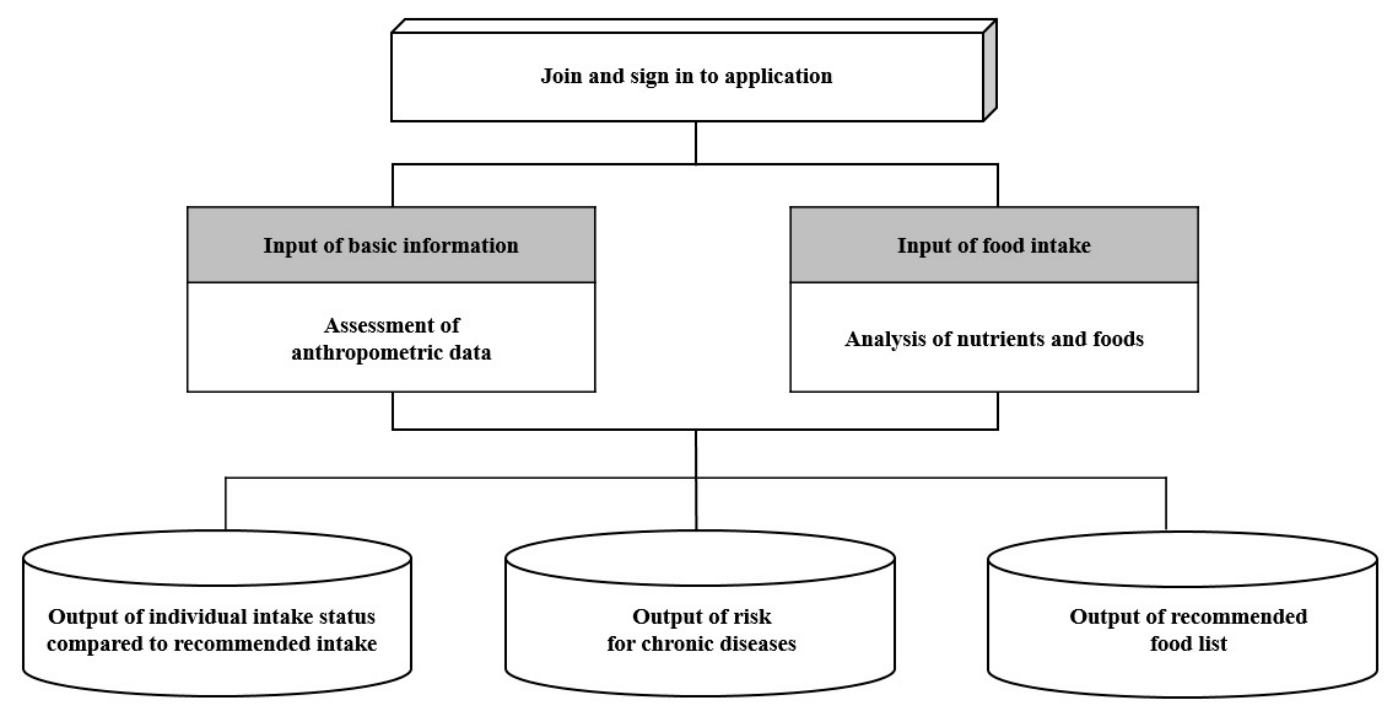

Figure 1. Flow chart of developing stage of application.

To provide a short message for disease prevention, we chose four major metabolic disorders-obesity, diabetes, hypertension and dyslipidemia—which are increasing in prevalence in Korea and are the major chronic disorders regularly reported by Korea Health Statistics. The Korea Health Statistics 2013: Korean National Health and Nutrition Examination Survey (KNHANES VI-1) reported that the prevalence of obesity (body mass index, BMI $\geq 25 \mathrm{~kg} / \mathrm{m}^{2}$ ), diabetes, hypertension, 
hypercholesterolemia and hypertriglyceridemia among Korean adults 30 years or older was $32.5 \%$, $11.9 \%, 30.4 \%, 15.9 \%$ and $17.6 \%$, respectively [14]. We selected four unfavorable nutrients: total energy intake for obesity, refined carbohydrates for diabetes, sodium for hypertension and saturated fat for dyslipidemia. Diet-A displayed the number of days these nutrients were consumed at levels above the reference over the last 7 days; if the number of days from 4 to 5, Diet-A alerted users of "high" disease risk, and if it ranged from 6 to 7 days, "very high". Additionally, the percentage of these nutrients relative to their recommended intake and foods or dishes that contributed that nutrient were displayed. Diet-A recommended five foods that contained low amounts of the aforementioned unfavorable nutrients, which were randomly selected in the same food groups for choices for the next meal.

\subsection{Intervention Study}

\subsubsection{Participants}

We recruited male and female high school students from one girls' high school and one boys' high school in Seoul, Korea. Eligibility criteria for this study were students who used a smartphone operating on Android and were willing to join. Twenty-four female and nine male students participated in this study. Among the 33 adolescents who met eligibility criteria, 13 female and 8 male students used the mobile application and reported on the feasibility (Figure 2). All 33 participants answered to pre- and post-intervention one-day $24-\mathrm{h}$ recalls and dietary habit questionnaires. All procedures were approved by the Sookmyung Women's University Institutional Review Board. Informed consent was obtained from the adolescent participants and their parents.

24 female and 9 male students, a total of 33 participants

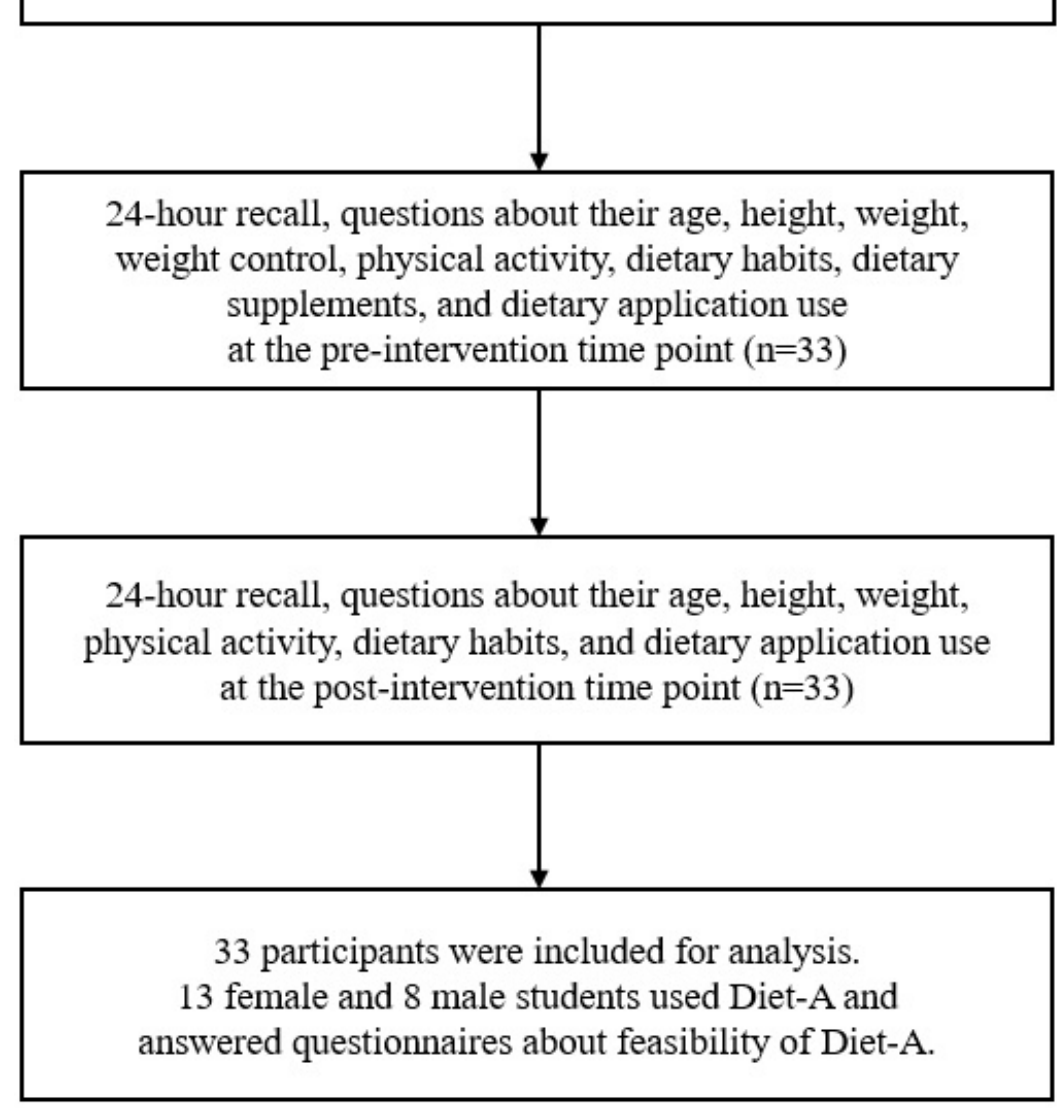

Figure 2. Flowchart of participants. 


\subsubsection{Questionnaires}

In the first session, a researcher explained the framework of the study and offered an explanatory note to participants. Participants answered the questions about their age, height, weight, weight control, physical activity, dietary habits, dietary supplements, and dietary application use at the pre-intervention time point. Participants were asked about number of days that participants engaged in vigorous physical activities such as jogging, climbing and cycling at fast speeds for at least $20 \mathrm{~min}$ at a time, during the last 7 days. Height and weight were self-reported, and body mass index (BMI) was calculated as body weight $(\mathrm{kg})$ divided by the square of the height $(\mathrm{m})$. Twenty-four-hour recalls were conducted by 5 to 6 trained interviewers at pre-intervention. After the researcher described the functions and how to use the application, participants downloaded the application on their mobile phones. Participants were instructed to record their dietary intake using Diet-A for three months and to record all the foods, dishes, and beverages that they consumed on that day, if they started recording their diet. We also asked interim questions about good and bad aspects of Diet-A and the reasons.

At post-intervention, participants completed questionnaires about the feasibility and usability of the application. The items on the feasibility questionnaire were adopted from previous feasibility studies of mobile diet applications [15-18]. Using a five-point Likert scale from 1 (totally disagree) to 5 (totally agree), twenty-one items were designed to measure the degree of satisfaction, convenience and efficiency. Dietary intake post-intervention was assessed using 24 -h recalls by trained interviewers. We calculated energy and nutrient intakes of foods and beverages obtained from 24-h recalls using the CAN-Pro 4.0 program [19].

\subsection{Statistical Analysis}

The demographic characteristics between male and female participants were compared using Fisher's exact test for categorical variables and the Wilcoxon rank-sum test for continuous variables. A paired $t$-test was used to compare the differences in estimated dietary intake between the two 24-h recalls and Diet-A. Nutrient intake from pre- and post-24-h recalls was compared using paired t-test. All statistical analyses in our study were performed using the SAS software package, version 9.4 (SAS Institute Inc., Cary, NC, USA), and all tests were evaluated using two-tailed tests of significance at the $p<0.05$ level.

\section{Results}

\subsection{Characteristics of Participants}

The demographic characteristics of all participants are shown in Table 1. Nine male and twenty-four female students participated in this study. The mean ages were 16.9 years (range: 16-17 years old) for male students and 17.4 years (range: 16-18 years old) for female students $(p=0.016)$. The mean BMIs were similar between male and female students. Among all participants, 8 male $(88.9 \%)$ and 13 female students (54.2\%) used the mobile application, Diet-A, in the study period. Dietary intake was recorded by Diet-A for an average of 12.2 days (range: 1-47 days) per participant with at least 1 meal per day and $87.9 \%$ of participants recorded at least 2 meals per day during the 3-month intervention period (Supplemental Table S1). 
Table 1. Baseline characteristics of adolescents enrolled in an intervention study of mobile application, Diet-A $(n=33)$.

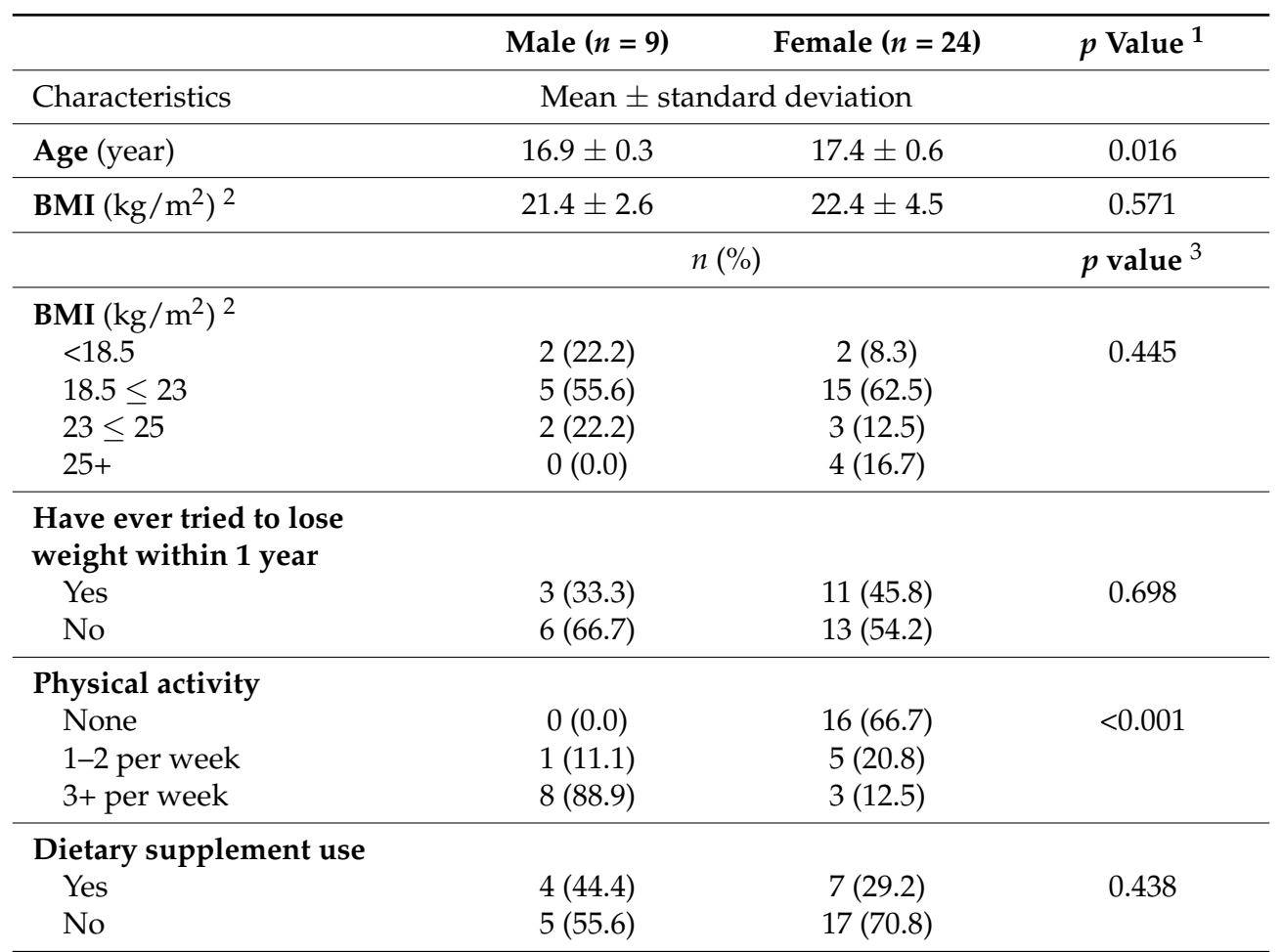

${ }^{1}$ Differences between male and female were analyzed using Wilcoxon rank sum test. ${ }^{2}$ Body mass index (BMI), calculated from self-reported weight and height $\left(\mathrm{kg} / \mathrm{m}^{2}\right) \cdot{ }^{3}$ Differences between male and female were analyzed using Fisher's exact test.

\subsection{Mean Nutrient Intake Estimated by Diet-A and 24-h Recalls}

Mean nutrient intakes estimated by the Diet-A and 24-h recalls are shown in Table 2. When we compared the mean values of pre- and post-24-h recalls with Diet-A, the differences between the two methods were statistically significant in energy, carbohydrates, protein, fat, sodium and calcium. The nutrient intakes estimated by Diet-A were lower than those obtained from 24-h recalls. There was no significant difference except for fat and calcium in the male group. However, the results in the female group were similar to those of the total group.

Table 2. Comparison of the nutrient intake from Diet-A vs. nutrient intake from 24-h recalls among all male and female students $(n=21)$.

\begin{tabular}{|c|c|c|c|}
\hline Nutrients & Diet-A $^{1}(n=21)$ & 24-h Recalls ${ }^{2}(n=21)$ & $p$ Value $^{3}$ \\
\hline \multicolumn{4}{|c|}{ mean \pm standard deviation } \\
\hline Energy (kcal/day) & $1427 \pm 379$ & $1893 \pm 394$ & 0.002 \\
\hline Carbohydrates (g/day) & $198.8 \pm 48.8$ & $255.6 \pm 54.6$ & 0.003 \\
\hline Protein (g/day) & $50.5 \pm 19.4$ & $76.2 \pm 25.3$ & 0.002 \\
\hline Total fat (g/day) & $38.8 \pm 15.6$ & $62.0 \pm 21.2$ & $<0.001$ \\
\hline Sodium (mg/day) & $2436.8 \pm 956.3$ & $3204.7 \pm 1090.6$ & 0.020 \\
\hline Saturated fat (g/day) & $11.4 \pm 4.0$ & $13.2 \pm 8.7$ & 0.390 \\
\hline Calcium (mg/day) & $225.4 \pm 105.0$ & $511.0 \pm 312.1$ & $<0.001$ \\
\hline Iron (mg/day) & $11.3 \pm 6.7$ & $13.5 \pm 4.8$ & 0.210 \\
\hline
\end{tabular}

1 The average of number of days that participants used Diet-A was 12.2 days (interquartile range: 6-14 days). ${ }^{2}$ Mean values of two 24 -h recalls were estimated by the CAN-Pro 4.0 program. ${ }^{3}$ Differences between two dietary assessment methods were analyzed using paired $t$-test. 


\subsection{Comparison of the Mean Nutrient Intake Between the Pre- and Post-24-h Recalls}

The mean values of energy and nutrient intakes estimated by pre- and post-intervention $24-h$ recalls were comparable, as shown in Table 3. In the 24-h recall after the intervention, there were statistically significant decreases in sodium $(p=0.040)$ and calcium $(p=0.034)$ compared with the 24-h recall before the intervention. For other nutrients, we did not find significant differences between pre- and post-intervention. In the $24-\mathrm{h}$ recall after the intervention, one male and one female student reported that they suffered from gastritis and enteritis, and one of the girls reported that she had tried a one-meal-a-day diet. When we conducted a sensitivity analysis by excluding these three participants, we did not observe significant differences in any of the nutrients between pre- and post-intervention 24-h recalls.

Table 3. Comparison of the nutrient intake from pre- and post-24-h recalls among all male and female students $(n=33)$.

\begin{tabular}{lccc}
\hline Nutrients & $\begin{array}{c}\text { 24-h Recall at } \\
\text { Pre-Intervention }(\boldsymbol{n}=\mathbf{3 3})\end{array}$ & $\begin{array}{c}\text { 24-h Recall at } \\
\text { Post-Intervention }(\boldsymbol{n}=\mathbf{3 3})\end{array}$ & ${\boldsymbol{p ~ V a l u e ~} \mathbf{1}^{\mathbf{1}}}$ \\
\hline & \multicolumn{2}{c}{ Mean \pm standard deviation } & \\
Energy (kcal/day) & $1929 \pm 668$ & $1696 \pm 593$ & 0.107 \\
Carbohydrates (g/day) & $261.3 \pm 70.9$ & $231.3 \pm 87.1$ & 0.068 \\
Protein (g/day) & $79.2 \pm 46.9$ & $64.8 \pm 26.0$ & 0.143 \\
Total fat (g/day) & $62.6 \pm 33.6$ & $55.1 \pm 25.8$ & 0.298 \\
Sodium (mg/day) & $3374.5 \pm 1869.0$ & $2567.1 \pm 1328.8$ & 0.040 \\
Saturated fat (g/day) & $10.9 \pm 9.2$ & $13.0 \pm 9.4$ & 0.280 \\
Calcium (mg/day) & $534.6 \pm 304.4$ & $390.0 \pm 361.0$ & 0.034 \\
Iron (mg/day) & $14.6 \pm 7.2$ & $11.4 \pm 6.3$ & 0.072 \\
\hline
\end{tabular}

There was a 3-month interval between pre-intervention and post-intervention. ${ }^{1}$ Differences between pre- and post-24-h recalls were analyzed using paired $t$-test.

On the interim questionnaire for compliance with Diet-A, we asked what good and bad things they found in using the mobile application $(n=9)$. They reported that they were able to get information about their dietary habits and eat meals at regular times. In addition, they believed that they increased their intake of vegetables and fruits and reduced their intake of fast food such as hamburgers or fried chicken during the intervention study. The participants also reported that the main reasons why they stopped using Diet-A were the burden of recording their meals every time they ate and a lack of some foods, such as new commercial products, in the database.

\subsection{Feasibility of Diet- $A$}

The feasibility results are presented in Table 4 . Of those who completed questionnaires $(n=21)$, $61.9 \%$ reported that they were satisfied using the application to monitor their dietary intake, and $65.0 \%$ of participants who answered in item 8 reported that this application was helpful for monitoring the food consumed. Additionally, $57.1 \%$ of participants slightly agreed or totally agreed that they were able to learn about their dietary intake during the period they used a Diet-A. However, when they were asked about the difficulties of application use, $71.4 \%$ reported that it was burdensome to record their diet and sometimes they did not remember to record their diet $(85.7 \%)$. 
Table 4. Agreement with items on the feasibility questionnaire about Diet-A use among application users $(n=21)$.

\begin{tabular}{|c|c|c|c|c|c|c|}
\hline Item & $n$ & $\begin{array}{c}\text { Totally } \\
\text { Disagree }\end{array}$ & $\begin{array}{l}\text { Slightly } \\
\text { Disagree }\end{array}$ & Neutral & $\begin{array}{c}\text { Slightly } \\
\text { Agree }\end{array}$ & $\begin{array}{l}\text { Totally } \\
\text { Agree }\end{array}$ \\
\hline & & & & $n(\%)$ & & \\
\hline 1. This application was an easy way to monitor my dietary intake & 21 & $1(4.8)$ & $3(14.3)$ & $8(38.1)$ & $6(28.6)$ & $3(14.3)$ \\
\hline 2. I learned about my dietary intake during the period I used Diet-A & 21 & $1(4.8)$ & $1(4.8)$ & $7(33.3)$ & $10(47.6)$ & $2(9.5)$ \\
\hline 3. The function of taking photographs helped me to remember the foods I ate & 20 & $3(15.0)$ & $3(15.0)$ & $7(35.0)$ & $6(30.0)$ & $1(5.0)$ \\
\hline 4. The voice recognizing function helped me to input what I ate in a convenient way & 20 & $5(25.0)$ & $7(35.0)$ & $5(25.0)$ & $3(15.0)$ & $0(0.0)$ \\
\hline 5. I was ashamed to use the voice recognition function & 20 & $3(15.0)$ & $4(20.0)$ & $6(30.0)$ & $4(20.0)$ & $3(15.0)$ \\
\hline 6. The application made me think about how to change my dietary intake & 21 & $1(4.8)$ & $3(14.3)$ & $9(42.9)$ & $6(28.6)$ & $2(9.5)$ \\
\hline 7. This application actually influenced my dietary habits & 21 & $1(4.8)$ & $5(23.8)$ & $9(42.9)$ & $4(19.1)$ & $2(9.5)$ \\
\hline 8. This application was helpful for monitoring the food consumed & 20 & $1(5.0)$ & $1(5.0)$ & $5(25.0)$ & $9(45.0)$ & $4(20.0)$ \\
\hline 9. The application was easy to use & 21 & $3(14.3)$ & $7(33.3)$ & $3(14.3)$ & $4(19.1)$ & $4(19.1)$ \\
\hline 10. I was able to get enough clues about meaning of each menu & 21 & $1(4.8)$ & $2(9.5)$ & $10(47.6)$ & $7(33.3)$ & $1(4.8)$ \\
\hline 11. It was helpful to manage my dietary intake using the application & 21 & $1(4.8)$ & $3(14.3)$ & $9(42.9)$ & $6(28.6)$ & $2(9.5)$ \\
\hline 12. I was able to quickly find the menu that I need from the application & 21 & $4(19.1)$ & $5(23.8)$ & $6(28.6)$ & $4(19.1)$ & $2(9.5)$ \\
\hline 13. The information provided on the application was easy to understand & 21 & $2(9.5)$ & $5(23.8)$ & $5(23.8)$ & $6(28.6)$ & $3(14.3)$ \\
\hline 14. The information provided on the application was helpful & 21 & $1(4.8)$ & $1(4.8)$ & $11(52.4)$ & $7(33.3)$ & $1(4.8)$ \\
\hline 15. I enjoyed using the application & 21 & $2(9.5)$ & $4(19.1)$ & $8(38.1)$ & $6(28.6)$ & $1(4.8)$ \\
\hline 16. I was satisfied with using the application to monitor my dietary intake & 21 & $1(4.8)$ & $4(19.1)$ & $3(14.3)$ & $11(52.4)$ & $2(9.5)$ \\
\hline 17. I liked getting customized information about my dietary intake & 21 & $1(4.8)$ & $3(14.3)$ & $7(33.3)$ & $9(42.9)$ & $1(4.8)$ \\
\hline 18. This application interfered with my daily life & 21 & $6(28.6)$ & $10(47.6)$ & $3(14.3)$ & $1(4.8)$ & $1(4.8)$ \\
\hline 19. It took a long time to use this application & 21 & $2(9.5)$ & $4(19.1)$ & $8(38.1)$ & $6(28.6)$ & $1(4.8)$ \\
\hline 20. It was burdensome to use this application & 21 & $0(0.0)$ & $3(14.3)$ & $3(14.3)$ & $12(57.1)$ & $3(14.3)$ \\
\hline 21. Sometimes, I had trouble remembering to record my dietary intake & 21 & $0(0.0)$ & $1(4.8)$ & $2(9.5)$ & $11(52.4)$ & $7(33.3)$ \\
\hline
\end{tabular}




\section{Discussion}

We developed a mobile application called 'Diet- $A$ ' that was designed to record dietary intake and provide users with real-time feedback. Diet-A provided real-time feedback on selected nutrients relative to the Korea Dietary Reference Intakes and a short message focusing on the prevention of obesity, diabetes, hypertension and dyslipidemia.

We selected total energy intake for obesity, refined carbohydrate intake for diabetes, sodium intake for hypertension and saturated fat for dyslipidemia based on the following evidence. A long-term excess of energy intake leads to obesity by altering the balance between energy intake and expenditure, and maintaining energy balance is a key strategy in the management of obesity [20]. For prevention of type 2 diabetes, the American Diabetes Association recommended that individuals choose whole-grain foods whenever possible instead of refined foods [21]. Several epidemiologic studies found a positive association between diabetes mellitus and refined grains, including in Asian populations [22]. Excess sodium intake leads to hypertension by increasing blood volume and peripheral vascular resistance. Dietary Approaches to Stop Hypertension (DASH) clinical trials have shown that sodium reduction lowers systolic and diastolic blood pressure levels [23]. Sodium intake is high in Koreans; according to KNHANES in 2013, 80.6\% of people over 9 years old consumed more sodium than the $2000 \mathrm{mg} /$ day that the WHO recommends [11]. Therefore, we emphasized sodium intake for hypertension prevention. Saturated fat intake is a risk factor for cardiovascular disease, possibly through modulation of lipid metabolism. A meta-analysis of 60 controlled trials reported that the ratio of total to High-Density Lipoprotein (HDL) cholesterol decreased if saturated fat was replaced with unsaturated fat [24].

Accurate dietary assessment is essential for improving the feasibility of dietary mobile applications. Twenty-four-hour recall, food records, and food frequency questionnaires (FFQs) have been widely used for dietary assessment in epidemiology studies, but none of these methods estimate dietary intake without error $[25,26]$. Therefore, use of ICT has been suggested to improve dietary assessment [27]. Recent systematic reviews showed a favorable outlook on image-assisted dietary assessment with mobile devices, in that ICT devices could assist the assessment of foods not captured by traditional methods alone [28] with higher user satisfaction and preference than conventional methods [29]. In a study assessing the accuracy of a personal digital assistant (PDA)-based dietary assessment program, Beasley et al. found that use of the PDA decreased the burden on the researcher by removing the need for data entry of nutritional information from the food records [30]. A review of new technology indicated that use of digital methods such as voice recognition or images captured by camera showed promise for enhancing the accuracy of food records [31].

During the last few years, clinical trials for managing chronic diseases using ICT have been actively conducted. Use of websites or mobile devices as a self-monitoring system resulted in greater weight loss compared to conventional care in several weight loss intervention studies. In a 12-month randomized clinical trial of 69 obese adults, the PDA group lost over $3.8 \mathrm{~kg}$ more than the standard group [32]. David \& Rafiullah [33] systematically reviewed the recent clinical studies of the use of mobile health applications for diabetes management and reported that $76 \%$ of the 21 papers published from 2007 to 2014 showed a favorable effect on diabetes management.

Diet-A has features that help individuals improve their dietary habits, including real-time feedback on selected nutrients, disease risk, and food recommendations. Provision of real-time data allows users to read immediate feedback or to get individualized dietary advice. In our study, $65.0 \%$ of participants who answered the question reported that this application was the way they monitored their dietary intake, and $61.9 \%$ of participants reported satisfaction with realizing their own dietary intake. Although the adolescents in the study favorably answered that they were able to monitor their diet, the present study did not show improvement in their diet when we compared their diet pre- and post-intervention. We selected adolescents in this intervention study because we believed that a mobile application could be a better alternative approach to measure their diet compared to conventional methods because adolescents had more confidence in the use of mobile technology than 
adults [34,35]. However, nutrient intake estimated by Diet-A was lower than what was estimated by 24-h recalls in all nutrients. Possible explanations may include difficulty in finding time to record in the middle of busy schedules and low motivation for dietary improvement. In our study, $71.4 \%$ of participants agreed or totally agreed that the application was burdensome to use, and $85.7 \%$ of them reported that sometimes they forgot to record their intakes. Additionally, the limited database of new products could lead to some underestimation. Some studies have shown that adolescents are prone to reporting error because of their unstructured eating patterns and the appearance of altering their food intake to simplify recording [35-37].

The study has several limitations. First, the sample was small and unrepresentative of the general population. Second, this application did not include a function to measure the user's physical activity; estimated energy requirements were computed as 'low-active', assuming the typical exercise level of Korean high school students. It may be necessary to add a motion sensor function in future studies. We chose only one nutrient per disease for a short message targeting the prevention of metabolic disorders, but given that multiple factors play roles in the development of chronic disease, further studies are needed to implement various components.

\section{Conclusions}

Diet-A is developed to provide users with real-time feedback on their diet and assess food and nutrient intakes. Diet-A is equipped with voice recognition and photography functions for accurate recording. It focuses on four chronic diseases, namely, obesity, diabetes, hypertension, and dyslipidemia, providing users with real-time feedback. However, dietary recording remains burdensome even with the application. Overall, our study revealed some challenges with regard to the use of our mobile application for dietary assessment and self-management of dietary habit, including underestimation, promotion of motivation to use, and improvement of the food and dish database.

Supplementary Materials: The following are available online at www.mdpi.com/2072-6643/9/7/748/s1, Table S1: The number of days and the number of meals that adolescents recorded in an intervention study of mobile application, Diet-A $(n=21)$.

Acknowledgments: This research was supported by the MSIP (Ministry of Science, ICT and Future Planning), Korea, under the ITRC (Information Technology Research Center) support program (IITP-2017-2014-0-00720) supervised by the IITP (Institute for Information \& communications Technology Promotion).

Author Contributions: J.-E.L. and J.E.L. designed the study, recruited the participants, collected and analyzed the data, and drafted the article. S.S. recruited the participants, collected and analyzed the data. J.S.A. was involved in the acquisition and analyses of data. Y.K. obtained funding and provided technical support. J.E.L. obtained funding. All authors had full access to the data and revised and approved the article for publication.

Conflicts of Interest: The authors declare no conflict of interest.

\section{References}

1. WHO Western Pacific Region. Noncommunicable Diseases. Available online: http://www.wpro.who.int/ mediacentre/factsheets/fs20130311/en/ (accessed on 20 October 2016).

2. Lim, S.S.; Vos, T.; Flaxman, A.D.; Danaei, G.; Shibuya, K.; Adair-Rohani, H.; Amann, M.; Anderson, H.R.; Andrews, K.G.; Aryee, M.; et al. A comparative risk assessment of burden of disease and injury attributable to 67 risk factors and risk factor clusters in 21 regions, 1990-2010: A systematic analysis for the Global Burden of Disease Study 2010. Lancet 2012, 380, 2224-2260. [CrossRef]

3. World Health Organization. Global Action Plan for the Prevention and Control of Noncommunicable Diseases 2013-2020; WHO: Genova, Switzerland, 2013.

4. Thompson, F.E.; Subar, A.F. Dietary assessment methodology. In Nutrition in the Prevention and Treatment of Disease; Ann, M.C., Carol, J.B., Mario, G.F., Eds.; Academic Press: Salt Lake City, UT, USA, 2008; Volume 2, pp. 3-39. 
5. Spring, B.; Pellegrini, C.A.; Pfammatter, A.; Duncan, J.M.; Pictor, A.; McFadden, H.; Siddique, J.; Hedeker, D. Effects of an abbreviated obesity intervention supported by mobile technology: The ENGAGED randomized clinical trial. Obesity 2017, 25, 1191-1198. [CrossRef] [PubMed]

6. Carter, M.C.; Burley, V.J.; Nykjaer, C.; Cade, J.E. Adherence to a smartphone application for weight loss compared to website and paper diary: Pilot randomized controlled trial. J. Med. Int. Res. 2013, 15, e32. [CrossRef] [PubMed]

7. KT DIGIECO. 2015 Mobile Trend; KT DIGIECO: Seoul, Korea, 2015. Available online: http:/ /www.digieco.co. $\mathrm{kr} /$ KTFront/report/report_issue_trend_view.action?board_seq=10349\&board_id=issue_trend\# (accessed on 3 November 2016).

8. International Telecommunication Union (ITU). ICT Development Index 2015. Available online: http://www. itu.int/net4/ITU-D/idi/2015/index.html (accessed on 3 November 2016).

9. Oh, Y.; Choi, J.; Jeon, Y.; Kim, Y. A design of personalized daily nutrition feedback system for cultivating healthy eating habit. Autumn Conf. Korea Inf. Process. Soc. 2015, 22, 531-533.

10. Jeon, Y.; Oh, Y.; Choi, J.; Lee, J.; Kim, Y. A Design of Personal Chronic Disease Feedback System Using Analysis of Diet. Commun. Korean Inst. Inf. Sci. Eng. 2015, 12, 1491-1493.

11. Rural Development Administration, National Institute of Agricultural Sciences. Consumer Friendly Food Composition Table, 2nd Revision; Kyomunsa: Paju, Korea, 2013.

12. The Korean Nutrition Society. Dietary Reference Intakes for Koreans; The Korean Nutrition Society: Seoul, Korea, 2010.

13. Food and Nutrient Data System. Available online: http://www.foodsafetykorea.go.kr/portal/ healthyfoodlife/foodnutrient/simpleSearch.do (accessed on 25 October 2016).

14. Ministry of Health Welfare. Korea Health Statistics 2013: Korea National Health and Nutrition Examination Survey (KNHANES VI-1); Ministry of Health Welfare: Cheongju, Korea, 2013.

15. Gemming, L.; Doherty, A.; Kelly, P.; Utter, J.; Mhurchu, C.N. Feasibility of a SenseCam-assisted 24-h recall to reduce under-reporting of energy intake. Eur. J. Clin. Nutr. 2013, 67, 1095-1099. [CrossRef] [PubMed]

16. Welch, J.; Dowell, S.; Johnson, C.S. Feasibility of using a personal digital assistant to self-monitor diet and fluid intake: A pilot study. Nephrol. Nurs. J. 2007, 34, 43-48. [PubMed]

17. Tsai, C.C.; Lee, G.; Raab, F.; Norman, G.J.; Sohn, T.; Griswold, W.G.; Patrick, K. Usability and feasibility of PmEB: A mobile phone application for monitoring real time caloric balance. Mob. Netw. Appl. 2007, 12, 173-184. [CrossRef]

18. Zang, J.; Song, J.; Wang, Z.; Yao, C.; Ma, J.; Huang, C.; Zhu, Z.; Smith, L.P.; Du, S.; Hua, J. Acceptability and feasibility of smartphone-assisted $24 \mathrm{~h}$ recalls in the Chinese population. Public Health Nutr. 2015, 18, 3272-3277. [CrossRef] [PubMed]

19. The Korean Nutrition Society. Nutritional Assessment Program 'CAN-Pro 4.0' [CD-ROM]; The Korean Nutrition Society: Seoul, Korea, 2011.

20. Crowley, V.E.; Yeo, G.S.; O'Rahilly, S. Obesity therapy: Altering the energy intake-and-expenditure balance sheet. Nat. Rev. Drug Discov. 2002, 1, 276-286. [CrossRef] [PubMed]

21. Evert, A.B.; Boucher, J.L.; Cypress, M.; Dunbar, S.A.; Franz, M.J.; Mayer-Davis, E.J.; Neumiller, J.J.; Nwankwo, R.; Verdi, C.L.; Urbanski, P. Nutrition therapy recommendations for the management of adults with diabetes. Diabetes Care 2014, 37, S120-S143. [CrossRef] [PubMed]

22. Aune, D.; Norat, T.; Romundstad, P.; Vatten, L.J. Whole grain and refined grain consumption and the risk of type 2 diabetes: A systematic review and dose-response meta-analysis of cohort studies. Eur. J. Epidemiol. 2013, 28, 845-858. [CrossRef] [PubMed]

23. Sacks, F.M.; Svetkey, L.P.; Vollmer, W.M.; Appel, L.J.; Bray, G.A.; Harsha, D.; Obarzanek, E.; Conlin, P.R.; Miller, E.R.; Simons-Morton, D.G. Effects on blood pressure of reduced dietary sodium and the Dietary Approaches to Stop Hypertension (DASH) diet. N. Engl. J. Med. 2001, 344, 3-10. [CrossRef] [PubMed]

24. Mensink, R.P.; Zock, P.L.; Kester, A.D.; Katan, M.B. Effects of dietary fatty acids and carbohydrates on the ratio of serum total to HDL cholesterol and on serum lipids and apolipoproteins: A meta-analysis of 60 controlled trials. Am. J. Clin. Nutr. 2003, 77, 1146-1155. [PubMed]

25. Beaton, G.H. Approaches to analysis of dietary data: Relationship between planned analyses and choice of methodology. Am. J. Clin. Nutr. 1994, 59, S253-S261.

26. Willett, W. Nutritional Epidemiology, 3rd ed.; Oxford University Press: New York, NY, USA, 2012. 
27. Ngo, J.; Engelen, A.; Molag, M.; Roesle, J.; García-Segovia, P.; Serra-Majem, L. A review of the use of information and communication technologies for dietary assessment. Br. J. Nutr. 2009, 101, S102-S112. [CrossRef] [PubMed]

28. Gemming, L.; Utter, J.; Mhurchu, C.N. Image-assisted dietary assessment: A systematic review of the evidence. J. Acad. Nutr. Diet. 2015, 115, 64-77. [CrossRef] [PubMed]

29. Sharp, D.B.; Allman-Farinelli, M. Feasibility and validity of mobile phones to assess dietary intake. Nutrition 2014, 30, 1257-1266. [CrossRef] [PubMed]

30. Beasley, J.; Riley, W.T.; Jean-Mary, J. Accuracy of a PDA-based dietary assessment program. Nutrition 2005, 21, 672-677. [CrossRef] [PubMed]

31. Stumbo, P.J. New technology in dietary assessment: A review of digital methods in improving food record accuracy. Proc. Nutr. Soc. 2013, 72, 70-76. [CrossRef] [PubMed]

32. Spring, B.; Duncan, J.M.; Janke, E.A.; Kozak, A.T.; McFadden, H.G.; DeMott, A.; Pictor, A.; Epstein, L.H.; Siddique, J.; Pellegrini, C.A. Integrating technology into standard weight loss treatment: A randomized controlled trial. JAMA Intern. Med. 2013, 173, 105-111. [CrossRef] [PubMed]

33. David, S.; Rafiullah, M. Innovative health informatics as an effective modern strategy in diabetes management: A critical review. Int. J. Clin. Pract. 2016, 70, 434-449. [CrossRef] [PubMed]

34. Daugherty, B.L.; Schap, T.E.; Ettienne-Gittens, R.; Zhu, F.M.; Bosch, M.; Delp, E.J.; Ebert, D.S.; Kerr, D.A.; Boushey, C.J. Novel technologies for assessing dietary intake: Evaluating the usability of a mobile telephone food record among adults and adolescents. J. Med. Internet Res. 2012, 14, e58. [CrossRef] [PubMed]

35. Boushey, C.J.; Kerr, D.A.; Wright, J.; Lutes, K.D.; Ebert, D.S.; Delp, E.J. Use of technology in children's dietary assessment. Eur. J. Clin. Nutr. 2009, 63, S50-S57. [CrossRef] [PubMed]

36. Livingstone, M.; Robson, P.; Wallace, J. Issues in dietary intake assessment of children and adolescents. Br. J. Nutr. 2004, 92, S213-S222. [CrossRef] [PubMed]

37. Goodwin, R.A.; Brule, D.; Junkins, E.A.; Dubois, S.; Beer-Borst, S. Development of a food and activity record and a portion-size model booklet for use by 6- to 17-year olds: A review of focus-group testing. J. Am. Diet. Assoc. 2001, 101, 926-928. [CrossRef] 